DOI 10.37882/2500-3682.2020.07.14

\title{
ПСИХОФИЗИОЛОГИЧЕСКИЕ АСПЕКТЫ ТРЕВОГИ В СООТНОШЕНИИ С ПСИХИЧЕСКИМИ ПРОЦЕССАМИ ВОЗБУЖДЕНИЯ И ТОРМОЖЕНИЯ
}

\section{PSYCHOPHYSIOLOGICAL ASPECTS OF ANXIETY IN RELATION TO MENTAL PROCESSES OF EXCITATION AND INHIBITION}

\section{Maksimova}

Summary: The article considers the basic approaches to the problem of anxiety in the context of psychophysiology. The data of foreign studies are presented in the framework of the correlation of anxiety and mental processes of excitation and inhibition. Methods of stopping and reducing the risk of developing anxiety conditions are also provided.

Keywords: anxiety, anxiety disorders, psychophysiology, excitation, inhibition, autonomic nervous system, parasympathetic nervous system.

\section{Введение}

A нглийский поэт У.Х. Оден охарактеризовал XX век как «Эпоху беспокойства». Темпы нашей жизни стали еще быстрее с тех пор. Сейчас состояние преходящего беспокойства является неотъемлемой частью жизни. Теперь ощущение тревоги может настигнуть нас в любом, сколь угодно даже безопасном месте. Тревога хорошо известна каждому человеку, хотя для всех она представляет что-то свое. Люди страдают от проявления беспокойства различных форм: от мокрых рук до бессонницы. И иногда тревога настолько сильна, что оказывает большое влияние на нашу физиологию вплоть до неврологических расстройств. Связь между тревогой и телом была установлена во многих научных изысканиях. В этой статье я хотела бы обозначить позицию зарубежных исследователей относительно тревоги с точки зрения психофизиологии и в контексте представлений исследователей о психических процессах возбуждения и торможения.

\section{Актуальность исследования}

Тревога - это эмоция, характеризующаяся гнетущим состоянием внутреннего волнения, часто сопровождаемого нервозным поведением, таким как расхаживание назад-вперед, соматическими жалобами и навязчивыми мыслями. [8]

В более широком смысле, это страх перед будущим

\author{
Максимова Мария Васильевна \\ аспирант, Башкирский государственный университет \\ Maksimova8531@gmail.com
}

Аннотация: В статье рассматриваются основные подходы к проблеме тревоги в контексте психофизиологии. Представлены данные зарубежных исследований в рамках соотношения тревожности и психических процессов возбуждения и торможения. Также приводятся методики купирования и снижения риска развития тревожных состояний.

Ключевые слова: тревога, тревожные расстройства, психофизиология, возбуждение, торможение, вегетативная нервная система, парасимпатическая нервная система.

событием. Даже если причина для беспокойства лежит в прошлом, беспокойство о последствиях живет в будущем. Поэтому тревога и отличается от страха, поскольку второй - это когнитивный и эмоциональный ответ организма на угрозу в реальном времени. Другое отличие состоит в том, что страх имеет объективную природу, а тревога - размытое и неопределенное опасение. Это чувство беспокойства, обычно обобщенное и не сфокусированное как чрезмерная реакция на ситуацию, которая только субъективно рассматривается как угрожающая.

Чтобы понять природу этого процесса, мы должны обратиться к его происхождению. Л.Ш. Куби назвал тревогу мостом между паттерном испуга и рассветом всех процессов мышления. Неврологически, реакция испуга включает в себя торможение высших нервных центров, которые не могут интегрировать стимул такой внезапности. Другими словами, реакция испуга наступает прежде, чем осознание того, что нам угрожает. К. Лэндис и У.Э. Хант описали шаблон испуга как преэмоциональный. Он рассматривается как первичный, безусловный защитный ответ, предшественник эмоциональных реакций организма, которые впоследствии становятся тревогой и страхом. [7]

3. Фрейд различал два типа тревоги, известные как «уместный» и «неуместный». Между ними есть тонкая грань в том месте, где это чувство становится не помощником, а врагом. Эволюционно способность испытывать страх возникла для защиты. В ситуации опасности мы 
должны быть в состоянии распознать угрозу и сделать все возможное, чтобы защитить себя. Следовательно, механизм тревоги был призван для выживания. Но даже системы, которые кажутся совершенными, имеют свои недостатки. Обратная сторона заключается в тревожных расстройствах.

\section{Основная часть исследования}

Согласно последней версии Руководства по диагностике и статистике психических расстройств (DSM-IV-TR) существует одиннадцать типов тревожных состояний. Некоторые из них носят кратковременный характер и часто купируются путем избавления от стрессора. [5] Эта категория включает в себя острое стрессовое расстройство, расстройство адаптации с тревожными признаками и вызванное психоактивными веществами тревожное расстройство.

Долгосрочные тревожные расстройства отличаются тенденцией к расширению. Многие из них берут свое начало в детстве и продолжают довлеть над индивидом во зрелом возрасте, особенно если тот не обращался за лечением. Эта категория представлена генерализованным тревожным расстройством (ГТР), обсессивно-компульсивным расстройством (ОКС), паническим расстройством, посттравматическим стрессовым расстройством (ПТСР) и фобиями и т.д.

Будучи частью нашего естественного защитного механизма, тревога активирует вегетативную нервную систему. Существует явление, известное как реакция «бей или беги», которое является общим для всех млекопитающих и большинства других животных. Данный ответ организма основан на адреналине и может быть описан через различные телесные симптомы. Более конкретно, мозговое вещество надпочечников производит гормональный каскад, который приводит к секреции катехоламинов, особенно норэпинефрина и адреналина [3]. Гормоны кортизол, эстроген и тестостерон, а также нейротрансмиттеры, серотонин и дофамин, также влияют на то, как организм реагирует на опасную ситуацию. Физиологические изменения, которые происходят во время «боя» или «бегства», активируются, чтобы дать телу увеличенную силу и скорость в ожидании грядущего ответа.

Физические симптомы тревоги имеют различные формы, такие как учащенный пульс, одышка, боль/стеснение в груди, потливость, раздражительность, приступы паники, учащённое сердцебиение, поверхностное дыхание, сухость во рту, дрожь, удушье, головные боли, бессонница, неконтролируемое напряжение мышц, подергивания, ощущение слабости/нереальности, покалывания в руках/ногах, стеснение в горле, проблемы с речью, страх смерти, сумасшествие и потеря контроля.
Рассмотрим процесс, проиллюстрированный на примере одного из самых распространенных симптомов - мышечного напряжения. Наше тело накапливает энергию в мышцах в случае действия. Чем больше энергии сохраняется, тем больше мы ощущаем напряжение. Это может привести к неконтролируемому дрожанию, поскольку мышцы накапливают все больше и больше энергии. [4] Кровообращение играет большую роль в получении энергии. Через дыхание кровоток доставляет кислород по всему организму, а также другие питательные вещества в мышцы и ткани. Когда индивид испытываете беспокойство, тело нуждается в большем количестве топлива, и, следовательно, работа сердца и легких ускоряется. Это вызывает потоотделение как естественный механизм охлаждения, а также другие физические состояния, такие как вакуум в голове, из-за недостатка кислорода в мозге.

Чтобы обеспечить энергией наиболее важные для выживания части организма, такие как ноги, руки и мышцы живота, мозг решает сократить доставку крови в менее значимые области, такие как желудок и половые органы. Если мы находимся в опасной для жизни ситуации, мы вряд ли остановимся, чтобы поесть или заняться сексом. Это может объяснить тот факт, почему люди, пребывающие в состоянии длительного стресса, могут ощущать тошноту или отказываться от интимной активности. [1] Также это объясняет, почему иногда люди испытывают ощущение бабочек и бурление в желудке. Все эти физические явления показывают, что система работает эффективно для обеспечения нашей безопасности.

Еще одним признаком правильной работы организма является своевременная реакция парасимпатической нервной системы. Она отвечает за то, чтобы снова успокоить тело. Это выключатель. Как только угроза исчезает, запускается парасимпатическая нервная система для восстановления нормального функционирования.

Когда человек постоянно испытывает стресс, его тело никогда не получает сигнал вернуться к норме. В этом случае иммунная система может быть ослаблена, что делает организм более уязвимым для вирусных инфекций. По данным Гарвардской медицинской школы, исследования показали повышенный уровень тревожности и панических атак у людей с хроническими респираторными заболеваниями. Чаще бывают госпитализированы больные хроническим обструктивным заболеванием легких с выявленной тревожностью. [6]

Выделительная и пищеварительная системы человека также подвержены тревоге. Существуют данные о наличии связи между тревожными расстройствами и развитием синдрома раздраженного кишечника (СРК), который может быть причиной рвоты и диареи. Спектр потенциальных проблем довольно широкий. Человек 
может страдать от потери аппетита, спазмов в животе, запоров или проблем с секрецией желчного пузыря и поджелудочной железы.

Часто повторяющиеся приступы паники могут привести к страху перед самими приступами, тем самым лишь усиливая общую тревогу. Высокий уровень стресса может вызвать клинические симптомы депрессии. Даже при хорошей генетике есть шансы получить диабет или высокое кровяное давление. И, конечно же, к сожалению, большему риску подвержены люди, уже имеющие сердечно-сосудистые заболевания или другие проблемы со здоровьем.

В наше время существует бесчисленное множество способов справиться с нашими заботами. Многие из них существуют в рамках психотерапевтических подходов. Вероятно, наиболее популярной является когнитивноповеденческая терапия (КПТ), которая фокусируется на разработке стратегий личного преодоления, направленных на решение текущих проблем и изменение неэффективных моделей в познании (например, мысли, убеждения и отношения), поведении и эмоциональной регуляции. [2] КПТ бросает вызов автоматическим вредным мыслям о типе тела, характере, жизненных условиях, социальной роли и многих других предполагаемых проблемах и изучает более гибкий и реалистичный способ мышления. Термин «воздействие in vivo» относится к прямому столкновению пациента с опасными объектами, действиями или ситуациями. Например, если человек борется с социальным тревожным расстройством, психотерапевт может дать задание выступить на публике, т.е. прямо противостоять своим страхам. Использование КПТ значительно уменьшило число эпизодов выявления генерализованного тревожного расстройства и прочих симптомов тревоги. [9]

Другие методы лежат в области популярной психологии. Обычно они сосредоточены вокруг дыхания и мышечной релаксации, и не требуют специфического оборудования. Все, что необходимо - это простые упражнения, которые легко выполнять буквально везде. С другой стороны, некоторые из них достаточно сложны, как расслабление Джекобсона и более продвинутая трансцендентальная медитация. Они требуют больше времени и дополнительных знаний для достижения максимального результата.

Хорошим примером повседневных средств совладания с тревожными состояниями является брюшное дыхание. Как первая помощь в борьбе с беспокойством и паническими ощущениями - это неоценимо. Одна из самых простых вещей - научиться правильно дышать, поскольку это помогает снизить выработку адреналина. Зачастую, мы все дышим довольно неглубоко, что может быть причиной неправильного уровня углекислого газа и кислорода в крови человека. В этом случае мозг может интерпретировать это поверхностное дыхание как признак опасности. Соответственно, когда возникает паника, нужно научиться дышать как можно глубже до самых низов легких. Тогда правильный обмен газа будет восстановлен. Этот метод подразумевает расширение живота человека и втягивание воздуха в легкие. Индивид должен задержать дыхание на несколько секунд, а затем медленно выдохнуть. За этим упражнением может следовать легкое головокружение, которое совершенно нормально, потому что это указывает на то, что газообмен в организме происходит на должном уровне. Для достижения оптимального эффекта эту практику следует повторять не менее трех раз в час. Таким образом, поверхностное и брюшное дыхание во время сильного беспокойства помогут контролировать их проявления тревоги. [1]

Еще один способ помочь организму свести к минимуму разрушительное воздействие беспокойства - это диета. Дефицит питательных веществ может негативно влиять на центральную нервную систему, что опять же может усугубить беспокойство. Диетологи советуют употреблять пищу, богатую витамином В. Это класс водорастворимых витаминов, которые играют важную роль в метаболизме клеток. Молоко и молочные продукты, такие как йогурт и сыр, являются источником рибофлавина. Цыпленок, индейка, лосось и другая рыба, включая консервированный тунец, являются отличными природными источниками ниацина. Обогащенные зерновые, бобовые, арахис, макароны и цельнозерновая пшеница также являются его источником. Ниацин способствует здоровой нервной функции, улучшает работу сердечно-сосудистой системы и способствует выработке энергии. [10] Все виды ягод приветствуются за их витамин С и биофлавоноиды. Также мед и сухофрукты - за наличие триптофана, который является незаменимым аминокислотным компонентом белка.

Также было предложено сократить потребление рафинированного сахара и меньше углеводов, пить меньше алкоголя и избегать продуктов, содержащих кофеин, таких как чай, кофе, газированные напитки, шоколад и т. д. [1] Если вы курите, рекомендуется также не курить слишком много, потому что никотин является стимулятором, который ускоряет сердцебиение. Такой запрос может показаться нереальным из-за растущей потребности в курении в ситуации беспокойства. Тем не менее, важно освободить ваше тело от любых возможных отягчающих факторов.

\section{Выводы}

Книги, журналы, интернет полны рекомендациями о том, как снизить беспокойство. Помимо упражнений и диет наиболее популярными стратегиями отвлечения 
являются спорт, танцы, рисование и другие виды деятельности. Молитва, улыбка и ромашковый чай также в списке. И, конечно, трудно переоценить присутствие друзей и членов семьи, которые могут создать ощущение безопасного места. Поддержка близких может стать настоящим лекарством.

Беспокойство легко проследить по изменениям в поведении индивида. Каждому человеку необходимо обращать пристальное внимание на собственные эмо- ции, переживания, и особенно на такие их проявления как раздражительность, перепады настроения и компульсивность. Трудности в концентрации и засыпании, а также усталость тоже являются частыми спутниками тревожности. Изменения в стереотипах поведения и мышления необходимы для качественного перехода от изнуряющей тревоги к более свободному и продуктивному функционированию организма не на пределе его возможностей.

\section{ЛИТЕРАТУРА}

1. Anxiety Care UK. The Biological Effects and Consequences of Anxiety. Available at: http://www.anxietycare.org.uk/docs/biologicaleffects.asp

2. Beck, J.S. (2011) Cognitive behavior therapy: Basics and beyond. 2nd ed. New York, NY: The Guilford Press.

3. Cannon, W. B. (1915) Bodily Changes in Pain, Hunger, Fear and Rage: An Account of Recent Researches into the Function of Emotional Excitement. AppletonCentury-Crofts.

4. DBT Self help. Anxiety management. Available at: https://www.dbtselfhelp.com/html/anxiety_management.html

5. Healthy Place. Types of Anxiety Disorders. Available at: https://www.healthyplace.com/anxiety-panic/anxiety-disorders/types-of-anxiety-disorders-list-ofanxiety-disorders/

6. Harvard Health (2008, July) Anxiety and physical illness. Available at: http://www.health.harvard.edu/newsletters/Harvard_Womens_Health_Watch/2008/July/ Anxiety_and_physical_illness

7. May, R. (2015) The meaning of anxiety. W. W. Norton \& Company.

8. Seligman, M.E.P.; Walker, E.F.; Rosenhan, D.L. (2000) Abnormal psychology. 4th ed. New York: W. W. Norton \& Company.

9. Seligman, M.E.P.; Schulman, P.; Derubeis, R.J.; Hollon, S.D. (1999) 'The prevention of depression and anxiety'. Prevention \& Treatment, 2 (1).

10. Livestrong.com (2017) Foods That Are High in B Vitamins. Available at: https://www.livestrong.com/article/22253-foods-high-b-vitamins/

(c) Максимова Мария Васильевна (Maksimova8531@gmail.com).

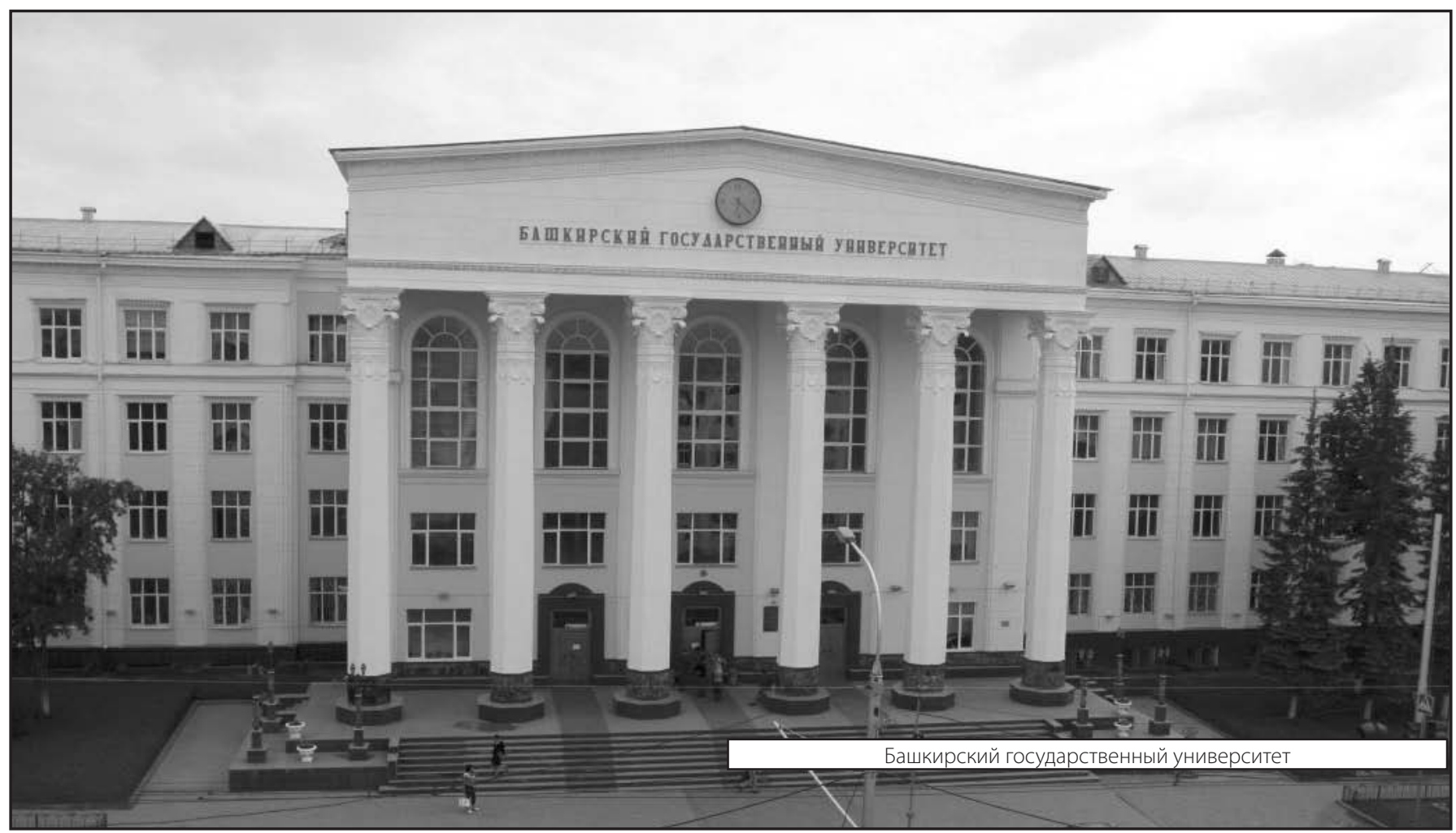

